\title{
CLINICAL PROFILE AND OUTCOME OF PATIENTS PRESENTING WITH ACUTE UPPER GI BLEEDING IN A TERTIARY CARE CENTRE OF WESTERN NEPAL
}

Shatdal Chaudhary ${ }^{1}$, Smriti Shakya ${ }^{2}$, Niraj Kumar Jaiswal ${ }^{1}$, Aakash Shahi ${ }^{3}$, Pushpa Raj Dhakal ${ }^{3}$, Nagendra Chaudhary ${ }^{4}$

\section{ABSTRACT}

\section{INTRODUCTION}

Acute upper gastrointestinal (UGI) bleeding is a common medical emergency which is associated with significant morbidity and mortality. The annual incidence of UGI bleeding varies from 48 to 160 cases per 100,000 populations in the United States of America (USA), with a mortality rate of $7 \%$ to $10 \%$. The aetiology and outcome of UGI bleeding varies significantly in different geographic regions depending on the demographic and socioeconomic characteristics of the local population. This study was done to evaluate the clinical profile and outcome of patients presenting with acute UGI bleeding at a tertiary care centre in Lumbini zone of Nepal.

\section{MATERIAL AND METHODS}

This was a hospital based prospective observational study. All the patients who presented with acute UGI bleeding and fulfilled the inclusion criteria from $1^{\text {st }}$ August 2013 to $31^{\text {st }}$ July 2014 were included in the study. The study was cleared by the ethical review committee of the institute and written informed consent was taken from all the patients.

\section{RESULTS}

During the study period, 70 patients fulfilled the inclusion criteria and were subjected to statistical analysis. The mean age of patients in the present study was $55.11 \pm 19.93$ years. The majority of patients $(30,43 \%)$ were elder, belonging to the age group of more than 60 years. There were $55(79 \%)$ male and $15(21 \%)$ female. The patients were mostly farmers by occupation accounting 29 (41\%) cases. Ethnically, 26 (37\%) patients of UGI bleeding were from janajati group where majority of them had esophageal varices. Overall, the peptic ulcer disease was the leading cause of UGI bleeding seen in 26 $(37 \%)$ patients followed by esophageal varices seen in $23(33 \%)$ patients. O positive was the commonest blood group which was found in $28(40 \%)$ of our patients. In our study $44(63 \%)$ patients were alcohol consumers and $37(53 \%)$ had coexisting comorbidities that added for the UGI bleeding related complications. During admission, 7 patients expired causing $10 \%$ mortality.

\section{CONCLUSIONS}

Acute UGI bleeding was commonly seen in older age group patients with male preponderance. Peptic ulcer disease was the leading cause of the UGI bleeding. The mortality rate was found to be $10 \%$. The mortality also increased with increasing age and patients with pre-existing co morbidities.

KEYWORDS Endoscopy, Peptic Ulcer; Upper GI Bleeding.

1 Associate Professor, Department of Internal Medicine, Universal College of Medical Sciences, Bhairahawa, Nepal

2 Senior Resident, Department of Cardiology, Manmohan Cardiothoracic Vascular and Transplant Center, Maharajgunj, Kathmandu, Nepal

3 Lecturer, Department of Internal Medicine, Universal College of Medical Sciences, Bhairahawa, Nepal

4 Professor, Department of Internal Medicine, Universal College of Medical Sciences, Bhairahawa, Nepal

\author{
For Correspondence \\ Dr. Shatdal Chaudhary \\ Associate Professor \\ Department of Internal Medicine, \\ Universal College of Medical Sciences, \\ Ranigaon, Bhairahawa, Nepal. \\ Email: shatdalchaudhary@yahoo.com
}




\section{INTRODUCTION}

Upper gastrointestinal (UGI) bleeding refers to loss of blood within the intraluminal gastrointestinal tract from any location between the upper oesophagus to the duodenum at the level of the ligament of treitz. ${ }^{1}$ It is a common medical emergency which is associated with significant morbidity and mortality.,3 The annual incidence of UGI bleeding ranges from 48 to 160 cases per 100,000 population with a higher incidence in men than in women in United States. ${ }^{4}$ Upper GI bleeding is responsible for more than 300,000 hospital admissions annually in the USA, with a mortality rate of $7 \%$ to $10 \%{ }^{5}$ In United Kingdom, it has an incidence ranging from approximately 50 to 150 per 100,000 of the population each year. The incidence is highest in areas of the lowest socioeconomic status. ${ }^{6,7}$

Bleeding from the upper gastrointestinal tract may present as hematemesis, melena, hematochezia, occult gastrointestinal bleeding, and anemia. The upper gastrointestinal bleeding presents with a wide spectrum of clinical severity, that ranges from insignificant bleeding to catastrophic exsanguinating hemorrhage. ${ }^{8}$ Approximately $80-85 \%$ of upper GI bleedings stop spontaneously without the need of specific therapy. ${ }^{9,10}$ In the remaining $15-20 \%$ of cases, bleeding continues or recurrent bleeding develops, and these patients have high morbidity and mortality. ${ }^{11}$

The etiology and outcome of upper GI bleeding varies significantly in different geographic regions depending on the demographic and socioeconomic characteristics of the local population. ${ }^{12}$ The common causes include duodenal ulcer, gastric ulcer, erosive mucosal disease, varices of portal hypertension and Mallory Weiss syndrome. Other less common causes include esophagitis, neoplasm and angiodysplasia. ${ }^{13}$ The contributions of these different etiologies have changed over time in many countries, for example, due to $\mathrm{H}$. pylori eradication therapy for peptic ulcer and the changes over time in alcohol consumption. ${ }^{14}$ Thus, there is need of more local studies to recognize the clinical profile, etiology and outcome of such patients especially in developing countries like Nepal, where upper gastrointestinal bleeding is considered a major burden of morbidity and mortality.

\section{MATERIAL AND METHODS}

This study was carried out in the Internal Medicine and Emergency Departments of Universal College of Medical Sciences, Bhairahawa, Nepal from $1^{\text {st }}$ August 2013 to $31^{\text {st }}$ July 2014. It was a prospective observational study. This study was cleared by the ethical review committee of the institute. Written informed consent was taken from all the patients. All the patients aged $>16$ years presenting with acute upper GI bleeding in and outpatient facility of Universal College of Medical Sciences Teaching Hospital were included in the study. The patients found to have conditions listed in box 1 were excluded from the study.

\section{Box 1. Exclusion criteria}

1. Patients who do not give written consent for the study.

2. Patients aged $\leq 16$ years

3. Those patients who presented with upper gastrointestinal bleeding but expired before performing upper gastrointestinal endoscopy

4. Those patients who were seropositive for HIV, Hepatitis B and C

After enrolment in the study, as per predesigned proforma, detailed history including age, sex, ethnicity, occupation, duration of hospital stay, presenting features of hematemesis or melena, history of acid peptic disease, presence of cirrhosis, nonsteroidal anti-inflammatory drugs (NSAID) use, regular ingestion of low dose aspirin, steroids, co-morbidities, previous history of upper GI bleeding and cause of it as far as possible was taken. Detailed physical examination including general and systemic examination was performed. Laboratory tests such as blood group, complete blood count (CBC), prothrombin time (PT), liver function tests ( LFT), renal function test (RFT), sodium $(\mathrm{Na})$, potassium $(\mathrm{K})$, random blood sugar (RBS), hepatitis B surface antigen (HbsAg), antihepatitis $\mathrm{C}$ virus antibody (Anti HCV), human immune deficiency virus (HIV I \& II), electrocardiogram (ECG), chest $\mathrm{X}$-ray along with ultrasonography (USG) of abdomen and pelvis was done.

The upper gastrointestinal endoscopy was done in all cases on the same day of presentation, if they presented during working hours or the next immediate working day with intention to establish the diagnosis and to provide necessary therapeutic intervention(s) to achieve hemostasis if considered appropriate. But patients who were hemodynamically unstable, endoscopy was done after resuscitation and stabilization of the patients. Fujinon videoendoscope model no. EG-250WR5 was used for the endoscopy. The endoscopy was performed in the endoscopy room under 10\% lignocaine spray by an experienced endoscopist. Biopsy was taken from suspicious lesions when necessary. A daily follow-up of patients after admission was done with close monitoring in terms of vital sign, daily hemoglobin measurement, development of rebleeding and complications until their discharge. Any mortality during the hospital stay was registered. 
Any resuscitative effort such as blood transfusion, endoscopic interventions or surgery was registered. Data entry was done using Microsoft Excel 2010 and was transferred to data sheets of computer software program, Statistical package for social sciences (SPSS) version 19.0 for windows. Statistical data analysis was performed using the same version of SPSS.

Categorical data were expressed as frequencies and corresponding percentages using Microsoft Excel. Quantitative variables were presented as means ( \pm standard deviation). In inferential statistics, chi square test was applied to test the association and significant difference in proportion between categorical variables.

\section{RESULTS}

All 70 patients with acute upper gastrointestinal bleeding fulfilled the inclusion and exclusion criteria and were included in this study for final analysis. Mean age of the patients was $55.11 \pm 19.93$ years. There were $55(79 \%)$ male and $15(21 \%)$ female patients. The mean age of females with acute UGI bleeding was $62.4 \pm 20.03$ years and males was $53.13 \pm 19.61$ years. Female patients were having UGI bleeding quite later than male patients. There was ethnic variability among study patients. The majority of patients $26(37 \%)$ were from janajati group followed by brahmin/ chhetri group $18(26 \%)$ patients, madhesi $13(18 \%)$ muslim $4(6 \%)$, dalit $2(3 \%)$ and others 7 $(10 \%)$. The majority of patients $29(41 \%)$ were farmer followed by servicemen 16 (23\%), housewives $9(13 \%)$, business $7(10 \%)$, student $3(4 \%)$ and others $6(9 \%)$. The majority of patients $44(63 \%)$ were alcohol consumers whereas 26 (37\%) were non-alcoholic. There were 34 (49\%) smokers and 36 (51\%) non-smokers.

In our study, 18 patients $(26 \%)$ had history of use of NSAIDs. The distribution of different blood groups among study patients found that the majority of patients $28(40 \%)$ had $\mathrm{O}$ positive blood group, followed by A positive in 20 (28\%) patients, $\mathrm{B}$ positive in $11(16 \%)$ patients, $\mathrm{AB}$ positive in 7 $(10 \%)$ patients and O negative in $4(6 \%)$ patients. Different comorbidities were also recorded which include hypertension in $11(16 \%)$ patients, diabetes mellitus in $6(9 \%)$ patients, coronary artery disease in $4(6 \%)$ patients, renal failure in 11 $(16 \%)$ patients and liver failure $26(37 \%)$ patients. The various etiologic factors of acute UGI bleeding among study patients has shown that the majority of the patients $26(37 \%)$ had peptic ulcer disease, 17 (24\%) patients had duodenal ulcer and $9(13 \%)$ patients had gastric ulcer, 23 (33\%) patients had esophageal varices, $8(11 \%)$ patients had gastric erosions, 4 (6\%) patients had duodenal erosions, 2 (3\%) patients had esophagitis, $5(7 \%)$ patients had malignancy and $2(3 \%)$ patients had Mallory Weiss tear (figure 1).

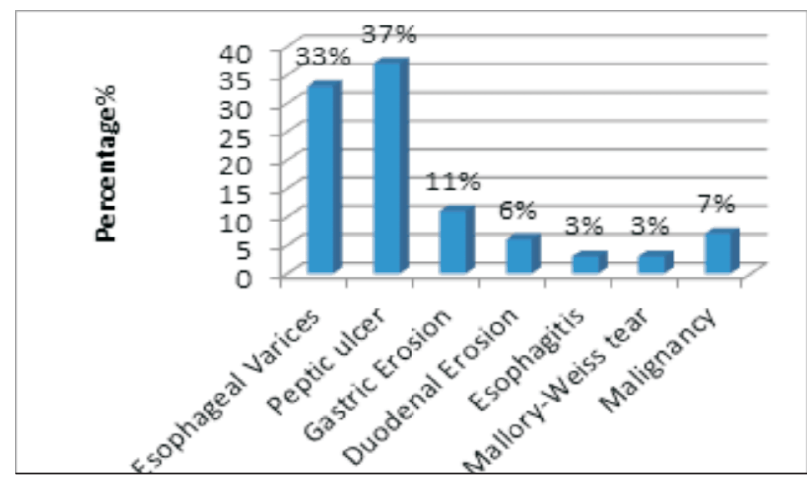

Fig 1. Various etiologies of acute UGI bleeding

Among 70 patients who presented with acute upper gastrointestinal bleeding, $7(10 \%)$ patients died in our study. It was shown that there was increased mortality among those patients who had acute UGI bleeding due to peptic ulcer disease which was found in 5 patients. One patient of esophageal varices and one patient of malignancy also died due to UGI bleeding. There was increased mortality among those patients who were more than 60 years of age. In our study $6(86 \%)$ patients who died were from this group. Among the study patients, there was mortality of $5(71 \%)$ patients who had coexisting co morbidities and $2(29 \%)$ patients did not have any of them. In our study $3(4 \%)$ patients with acute UGI Bleeding developed re-bleeding during hospital admission.

\section{DISCUSSION}

Acute UGI Bleeding is one of the common reasons for emergency hospital admissions and a major cause of morbidity and mortality. Acute UGI bleeding is defined as hematemesis or the passage of melena or laboratory evidence of blood loss from the upper gastrointestinal tract. Hematemesis is defined as vomiting of blood or blood clots. ${ }^{15}$ It includes vomiting of bright red blood, which suggests recent or ongoing bleeding, and dark material (coffee ground emesis), that suggests bleeding that stopped some time ago. ${ }^{16}$ It is a common presentation of UGI bleeding. In a prospective study from South Iran, it was seen in $68 \%$ of patients. ${ }^{17}$ Melena is defined as passage of black tarry stools as witnessed by medical staff or discovered on rectal examination. ${ }^{15}$ In a study from Bharatpur, Nepal, the presentation of UGI bleeding in form of both hematemesis and malena was seen in 86 patients $(71.7 \%)$, only melena in 24 patients $(20 \%)$ and only hematemesis in 10 patients $(8.3 \%){ }^{18}$

The UGI bleeding is categorized as variceal and non- variceal bleeding. Variceal bleeding results mostly from complications 
of end stage liver disease in our context, and non variceal bleeding is associated with peptic ulcer, erosions, Mallory Weiss tear, neoplasm, esophagitis, Dieulafoy's lesion, etc. They are diagnosed by endoscopy and are dealt with individually. This study showed that the mean age of study patients was $55.11 \pm 19.93$ years with majority of patients belonging to age group more than 60 years. In a study done by Bhattarai et al, the mean age of presentation of UGI bleeding was 49.6 years, ${ }^{19}$ whereas it was $48.76 \pm 17.19$ years in a study conducted by Dewan et al. ${ }^{18}$ In our study, the incidence of UGI bleeding was increased with increasing age that was statistically significant and there was male predominance 55 (79\%). In other parts of Nepal also, male predominance was reported by Bhattarai et al $71 \%{ }^{19}$ and Gurung et al $64.4 \%{ }^{20}$ Dewan et al $75 \% \cdot{ }^{18}$ In Nepal, various risk factors like smoking and alcohol consumption that are commoner in male population might have some role in the contribution to UGI bleeding.

The similar result was found in a study done at North India by Kashyap et al where $78.4 \%$ were male patients. ${ }^{21}$ This study showed that the UGI bleeding was present more in those patients who were farmers by occupation (41\%). This could thus be explained as since the study was done in terai region where agriculture is the main profession for livelihood, the patients presenting ought to be mostly farmers. As well as, the low socioeconomic status and poor hygiene of this group of patients could have predisposed them for higher incidence of UGI bleeding because of greater propensity of $H$. pylori infection. It was observed in this study that majority of patients presenting with upper gastrointestinal bleeding were from janajati group (37\%) including mainly the mongolians with least from dalit group (3\%).

The reason for this could be due to excessive consumption of alcohol among this ethnic population leading to alcohol liver disease causing esophageal varices. The overall commonest cause of UGI bleeding was peptic ulcer (37\%) followed by esophageal varices $(33 \%)$. In this study, $63 \%$ of the study patients were alcohol consumer and the incidence of the upper gastrointestinal bleeding was seen more in alcohol consumers showing a positive relation between them. Though the smoking habit was present in only about half of those patients presenting with UGI bleeding and only about $26 \%$ of the patients were taking NSAIDs, they could probably be attributed for the predisposition of peptic ulcer and erosive mucosal disease as important risk factors.

Endoscopy is the preferred investigative procedure for upper gastrointestinal bleeding because of its accuracy, low rate of complications, and potential for therapeutic intervention. Bleeding from a peptic ulcer remains the most common cause of upper gastrointestinal bleeding, accounting for approximately $50 \%$ of all cases of severe upper gastrointestinal bleeding. The rates of hemostasis that resulted from a first endoscopic procedure exceeded $94 \%$ in most large studies in which standardized techniques were used for thermocoagulation of bleeding lesions. Methods of achieving hemostasis include multipolar electrocoagulation, injection therapy, endoscopic laser therapy, hemoclipping, and ligation. The presence of comorbidities, organ failure and elderly age are the major risk factors for mortality due to upper gastrointestinal bleeding.

In a multicentre prospective survey by Rockall et al in 1995, it was found that the overall mortality was $14 \% .{ }^{15}$ In the emergency admissions, $65 \%$ of deaths in those aged under 80 were associated with malignancy or organ failure at presentation. Mortality for patients under 60 in the absence of malignancy or organ failure at presentation was $0.80 \%{ }^{22}$ It was also shown by a study done in Amsterdam by Vreeburg EM et al that the mortality rate was $13.9 \%$ in which most of them were related to advanced age, shock, and coexisting illnesses. $^{23}$

\section{CONCLUSION}

Acute UGI bleeding is mostly seen in patients with sixth decade of life and above with the mean age of 55.11 years with male predominance. The peptic ulcer disease is the leading cause of the UGI bleeding overall which occurred mainly in the patients with O Positive blood group.

The patients were mostly farmers by occupation and most of the suffering patients were from Janajati ethnic group who had commonly esophageal varices. The mortality rate was found to be $10 \%$ and there was significant relation between mortality with increasing age and presence of coexisting comorbidities.

\section{AKNOWLEDGEMENTS}

The authors are indebted to Endoscopy staffs of Universal College of Medical Sciences, Bhairahawa, for their help and support in carrying out this study.

CONFLICT OF INTEREST None to declare. 


\section{REFERENCE}

1. Juthaba R, Jensem DM. Acute Upper Gastrointestinal Bleeding. In: Friedman SL, Mc Quaid KR, Grendell JH (eds). Current Diagnosis \& Treatment in Gastroenterology. 2nd edition inc $2003 ; 53$.

2. Loren L. Gastrointestinal bleeding. In: Braunwald E, Fauci AS, Dasper DL, Hauser SL, Longo DL, Jameson JL (editors). Harrison's Principle of Internal medicine. USA: McGraw-Hill Companies Inc; $2005: 235$.

3. Silverstein FE, Gilbert DA, Tedesco FJ et al. The national ASGE survey on upper gastrointestinal bleeding. I. Study design and baseline data. Gastrointestinal Endoscopy. 1981; 27:73-9.

4. Longstrenth GF. Epidemiology of hospitalization for acute upper gastrointestinal hemorrhage: A population based study. Am J Gastroenterol 1995; 90(2):177-8.

5. Van Leerdam ME, Vreeburg EM, Rauws EA, Geraedts AM, Tijssen JP, Reitsma JB \& Tytgat GJ. Acute upper GI bleeding: Anything change?, Time trend analysis of incidence and outcome of acute upper GI bleeding between 1993/1994 and 2000. Am J Gastroenterol 2003; 98:1494-1499.

6. Elghuel A. The characteristics of adults with upper gastrointestinal bleeding admitted to tripoli medical center: A retrospective case-series analysis. Libyan JMed 2011; 6:6283.

7. Meaden C \& Makin AJ. Diagnosis and treatment of patients with gastrointestinal bleeding, Curr Anaesthesia Crit Care $2004 ; 15: 123-32$

8. Rockall TA, Logan, RA, Devlin HB \& Northfield TC. Selection of patients for early discharge or outpatient care after acute upper gastrointestinal haemorrhage. Lancet. 1996; $347: 1138-40$

9. Sarin N, Monga N \& Adams PC. Time to endoscopy and outcomes in upper gastrointestinal bleeding. Can $J$ Gastroenterol 2009; 23(7):489-493.

10. Kivkin K \& Lyakhovetskiy A. Treatment of non variceal upper gastrointestinal bleeding. Am J Health-Syst Pharm 2005; 62:1159-1170

11. Kankaria AG \& Fleischer DE. The critical care management of non-variceal upper gastrointestinal bleeding. Critical Care Clinics 1995; 11:347-68.

12. Theocharis G, Thomopoulos K, Sakellaropoulos G, Katsakoulis E \& Nikolopoulo V. Changing trends in the epidemiology and clinical outcome of acute upper gastrointestinal bleeding in a defined geographical area in Greece. JClin Gastroenterol 2008; 42:128-33.
13. Jeff WJ. The Washington Manual of Medical Therapeutics University School of Medicine, St. Louis, Missouri. Philadelphia and New York: Lippincott, Raven Publishers; 1998. Gastrointestinal Bleeding; p. 302-9.

14. Roberts SE, Button LA \& Williams JG. Prognosis Following Upper Gastrointestinal Bleeding. PLoS ONE 2012 Dec 12 7(12): e49507.

15. Rockall TA, Logen RF, Devlin HB, Northfield TC: Incidence of and mortality from acute gastrointestinal hemorrhage in the United Kingdom. Steering Committee \& members of National Audit of Acute Upper Gastrointestinal hemorrhage. Br Med J 1995; 311:222.

16. Thomas JS \& Dennis MJ. Gastrointestinal Bleeding. In: Mark F, Lawrence S, Friedman L \& Brandt J (editors). Sleisenger and Fordtran's Gastrointestinal and Liver Disease. $9^{\text {th }}$ edition. Vol 1A: Saunders Elsevier Inc; 2010: 285-321.

17. Kaviani MJ, Pirastehfar M, Azari A, Saberifiroozi M. Etiology and Outcome of Patients with Upper Gastrointestinal Bleeding: A Study from South of Iran. Saudi Journal of Gastroenterology;2012;16(4):253-259.

18. Dewan KR, Patowary BS \& Bhattarai S. A study of clinical and endoscopic profile of acute upper gastrointestinal bleeding. Kathmandu Univ Med J 2014; 45(1):21-25.

19. Bhattarai J, Acharya P, Barun B, Pokhrel S, Uprety N \& Shrestha NK. Comparison of endoscopic findings in patients from different ethnic groups undergoing endoscopy for upper gastrointestinal bleed in Eastern Nepal. NMCJ 2007; 9.

20. Gurung RB, Joshi G, Gautam N, Pant P, Pokrel B \& Koju RB. Upper gastrointestinal bleeding: Aetiology and demographic profile based on endoscopic examination at Dhulikhel Hospital, Katmandu University Hospital, Katmandu University Medical Journal 2010; 8(30): 208-211.

21. Kashyap R, Maharjan S, Sharma B, Jaret P, Patial RK, Rana S \& Pal LS. A clinical profile of acute upper gastrointestinal bleeding at moderate altitude. JIACM 2005; 6(3): 224-8.

22. Gostout CJ. Acute gastrointestinal bleeding-a common problem revisited. Mayo Clin Proc 1988; 63: 596-604.

23. Vreeburg EM \& Snel de Bruijne JW. Acute upper gastrointestinal bleeding in the Armsterdm area: Incidence, diagnosis \& clinical outcome. Am J Gastroenterol 1997; $92: 236$ 